\title{
Research on Freedom of Speech Based on Jurisprudence
}

\author{
Jing Luo \\ Xi'an Peihua University, Xi'an, Shaanxi 710125
}

Keywords: freedom of speech; jurisprudence; wisdom

\begin{abstract}
Freedom of speech is one of the most important characters and values of a society. A tolerant and free atmosphere can provide the basis for personal intellectual growth and harmonious social development. Since modern times, freedom of speech has been regarded as the basic human rights of citizens. Therefore, it is a common phenomenon to fix and protect them with constitutional laws. At the same time, solid theories are also necessary pillars to support a civil right. At present, the discussion of freedom of speech in the legal circles of our country is limited to the general theory, such as the subject, the object, the basic nature, etc. The overall understanding and meticulous combing of freedom of speech is still insufficient. The main purpose of this paper is to systematically examine the development of the entire liberalism by tracing the intellectual history and institutional history of free speech, trying to discover the positive components contained in it, completing a panoramic learning process, and then examining contemporary China. Legal practice, from this perspective, provides some ideas and views for studying the development of freedom of speech in Chinese society.
\end{abstract}

\section{Introduction}

The concept of freedom of speech can be traced back to ancient Greece. Ancient Greece was recognized as the cradle of Western civilization, and the free and open Apennine peninsula and the warm Mediterranean climate gave birth to the entire Western culture. In particular, the Athens city-state, which advocates rationality and freedom, is the first drop of milk to nourish the concept of freedom of speech. Athens is a city-state based on a high degree of direct democracy. There is ample evidence that the citizens of Athens in the fifth century BC were enthusiastic about participating in public political life and were keen to debate political issues. They believe that participation in public affairs is the natural duty and highest happiness of citizens. All activities carried out by the city state rely on the active cooperation of citizens, and the premise of these cooperation is to freely and fully debate all aspects of decision-making. For example, the citizen assembly is the highest authority of Athens. All male citizens who are 20 years old or older are Participants can participate. At the Citizens' Congress, participants are free to speak. Every citizen of Athens has the right to comment on the current resolution and any public officials. 1 The famous ancient Greek politician Pericles said: "In our view, the great obstacle to action is not the debate, but the lack of knowledge that can be obtained in the debate for the preparation of action. We have to do before the action. The special ability to think also has the special ability to take action, while others are ignorant and ignorant, but they are reluctant to think repeatedly. 2 In this country, the supremacy is the law, not the ruler. The freedom of citizens lies in his ability to fully understand the situation, to freely debate and to contribute. This identity is based not on status and wealth, but on talent and character. The ultimate goal of this freedom is to achieve a common life in which everyone can fully utilize and develop their talents and abilities.

\section{Value Analysis of Freedom of Speech}

Man is a rational and dignified being. A free person is regarded as a person who has normal reason to judge right and wrong and has moral ability to distinguish between good and evil, a person who can effectively self-control and self-control, and a person who can make his own choice. Such a person freely collects the information he needs, listens to the opinions he is interested in, 
then analyzes with rationality, and forms judgments based on his own experience, makes choices or decisions, and publishes his own opinions. Only in this way can we As a basis for the existence of human beings. 36 Freedom of speech is an indispensable element of personality development, the so-called essential attribute of human beings. "People are mainly distinguished from other animals by their spiritual characteristics. People use abstract terms to think, use language to convey their thoughts and feelings, and have the ability to form culture.... People develop their own ability to find their existence in the world. Meaning and status." Professor Emerson has emphasized that all people have the right to form their own beliefs and opinions in the development of their own personality. At the same time, he also has the right to express these beliefs and opinions. His performance is the development of thought, knowledge and self. Know the indispensable part. The expression of repressed beliefs and opinions is the insult to human dignity and the negation of human nature. On the one hand, suppressing speech is not conducive to the development of a person's intelligence. Because man is born with a self-realizing desire, he wants to display and develop his potential, and wants to express his different understandings of the world and the differences accumulated in his life journey. Experience with anyone else. He expects to express them not only by action but also by language; on the other hand, suppressing freedom is not conducive to the development of a person's virtue and the integrity of moral personality. If a person can't express his opinion or has to give up the belief he believes, the heart must be painful, and when his fear is punished and he has to express his opposition and even disgust, his personality begins to shrink. Therefore, the era of non-free speech must be an era of lie, personality distortion, and moral degradation. "Humans must become noble and beautiful objects of thinking, and cannot rely on all the personal things in themselves to be tempered. It is cultivated and promoted within the limits of the rights and interests of others." 38 Otherwise, human intelligence and virtue will have devastating consequences, and "the main factor that lacks human happiness" (Mil). Freedom of speech provides a necessary and normal environment for healthy growth.

Freedom of speech is a social "safety valve." By allowing the people to exercise their legal rights to freedom of expression and freedom of speech, let them express their will, release dissatisfaction, and enable the people to achieve psychological satisfaction and balance, so as to ease, decompose and even eliminate contradictions and confrontation, and avoid social shocks. The role. 48 Hegel once profoundly pointed out: "The principles of the modern world require that everyone should recognize something that shows him something that is entitled to recognition. In addition, everyone is willing to participate in discussions and deliberations. He did his duty, that is to say, published his opinion, his subjectivity was satisfied, and he would try to tolerate it. In France, it seems that freedom of speech is much less dangerous than silent, because behind In one case, the fear is that people will put their objections to things in their hearts. As for the arguments, they can have an exit and get satisfaction on the one hand, and let it make things easier along their own path. Advance." 49 It can be said that freedom of speech provides a condition that makes social progress not at the expense of social unrest.

The core of the modern constitutional system is the democratic politics under the premise of the rule of law. This concept is derived from the modern bourgeois revolution. It is theoretically derived from the theory of John Locke and others, that is, the government is based on the consent and authorization of the people. On the government, the government is the agent of the people. The sole purpose of public power is to guarantee the normal exercise of civil rights, and civil rights are the purpose of all political integration. Public decisions concerning the interests of citizens ultimately depend on the consent of the majority of citizens. From this, it is easy to deduce the value of the right to freedom of speech as a basic political right, that is, the freedom of speech in the perspective of political states and public power is also centered on the protection of civil rights. Of course, because it is also one of the civil rights, we can think that freedom of speech has both purpose and instrumental value. As an instrumental value, freedom of speech is to protect and fight for civil rights. As a purposeful value, freedom of speech is one of the goals of political society, as Dworkin said, "is the basic of a just political society. 


\section{Limit Theory of Freedom of Speech}

Freedom of speech is fundamentally a category of relationships that involves a wide range of interests between individuals and individuals, individuals and groups, groups and groups. It is difficult for pure self-speaking to constitute "freedom of speech" in the legal sense. In human society, "there are overlaps and conflicts between interests." 55 When a person expresses one's own beliefs in a certain way and realizes one's own desires, goals, or psychological requirements. It is very likely that this "free expression" will hinder or even infringe on other legitimate and reasonable interests. This is the so-called conflict of interest. In many cases, the conflicting interests do not have the problem of being good or bad, who is tall and who is low. So Pound said that people will face some fundamental problems in formulating, interpreting and applying laws, such as how to measure these benefits and how to evaluate them? What principles are used to determine the weight of each other? What interests should be given up in the event of a conflict? 56 Based on the above understanding, people agree that although freedom of speech is extremely important, it is not unrestricted at all times. In retrospect, even the most extreme liberals, whether both natural rightsists and utilitarians, admit that freedom and rights are not absolute and are subject to more or less restrictions. The exercise of freedom by individuals in society cannot prevent other equal subjects from exercising their freedom, that is, freedom can only be restricted for the sake of freedom, and equality is limited to freedom in order to achieve universal freedom in society.

Therefore, if the limits of freedom of speech cannot be properly explained, any theory supporting freedom of speech is one-sided and flawed, and it lacks sufficient persuasiveness and practical practical significance. The so-called limit here refers to the legal limit, not the material or moral limit. The material limit depends on the ability of people to understand, and the moral limit reflects the honesty and kindness of social ethics to the speaker. The legal limit shows that the speaker can freely express his speech without worrying about the boundary of the mandatory punishment of the law. Therefore, the limits of freedom of speech can also be said to be a number of restrictions imposed by law on speech.

The only basis for imposing restrictions on freedom of expression can only be the requirement of other legitimate rights, and it cannot therefore suppress the reasonable space for freedom of speech. "When we demand that private interests be sacrificed to the public interest and restrict freedom of speech, what we sacrifice may be a greater public interest. When we address the freedom to discuss public issues and other public interests - national security, public order The conflict between social good and the good should give the broadest space for freedom of speech and other public interests. This is not only because freedom of speech itself is a public interest, but because, fundamentally, the maintenance of other public interests It depends on freedom of speech, and the obstruction of freedom of speech is only temporary, partial and concrete." 57 Moreover, according to Professor Su Li's analysis of the conflict of rights (or "rights of rights") using the Coase Theorem, both parties to the conflict have the justification basis for their existence, and simply affirming one party may cause another One may be the damage to the right with greater potential value. Therefore, to study the limits of freedom of speech, we must incorporate the conflict of rights and the value theory of freedom of speech into the analytical framework.

\section{Conclusion}

As a basic citizen of constitutional citizenship, the theoretical system of freedom of speech must be supported by a solid social background and ideological foundation. The research attitude of China's intellectual circles on this issue is actually not very obvious to the true advancement of theoretical progress. Of course, this shortcoming also constitutes the direction and space of this article. Although it is limited by knowledge and often has a feeling of power, the author believes that this kind of effort is meaningful. Knowing why, you can prepare for action. 


\section{References}

[1] Guo Bin. Characteristics and Causes of Anti-corruption of Weibo in the Age of Media [J]. Theoretical Exploration, 2011(3): 118.

[2] Sun Daoxiang, Ren Jianming. Research on Anti-corruption Theory of Chinese Characteristics [M]. Beijing: China Founder Press, 2011:89.

[3] Xie Gengyu, Rong Ting. Correctly Guiding Weibo Public Opinion [J]. Modern Communication, 2011(5): 71.

[4] Lai Qing. The Evolution Mechanism of Microblog Public Opinion and the Guiding Strategy of Public Opinion [J]. Theoretical Exploration, 2011(3): 119.

[5] Shi Xiaojing. Analysis on the Countermeasures to Promote Anti-corruption in Weibo [J].Journal of Taiyuan Municipal Party School,2012(5):49. 